\title{
Do School Lunches Contribute to Childhood Obesity?
}

\author{
Diane Whitmore Schanzenbach \\ University of Chicago \\ October 2005
}

The most recent figures show that 16 percent of children aged 6-11 are obese - almost twice the rate of overweight in the early 1980s. Although there are few straightforward policy tools to combat the high level of obesity, almost two thirds of school children eat a National School Lunch Program lunch, and consume about one-third of their total calories from this meal. Previous studies have established that the school lunch program lunches often fail to meet nutrition requirements, and have an especially high fat content. In this project, I assess whether the National School Lunch Program plays a role in the incidence of childhood obesity. I employ two methods to isolate the causal impact of school lunches on childhood overweight. First, using panel data from the Early Childhood Longitudinal Survey I find that children who consume school lunches are about 2 percentile points more likely to be obese than those who brown bag their lunches. But since both groups of children enter kindergarten with the same obesity rates, the panel data suggests that the difference in obesity rates is not merely a function of fixed differences between children who select into the school lunch program. Second, I leverage the sharp discontinuity in eligibility for reduced-price lunch - available to children from families earning less than 185 percent of the poverty rate - to compare children just above and just below the eligibility cutoff. Using this regression discontinuity approach, I find that students are more likely to eat school lunch, to be obese, and weigh more if they are income-eligible for reduced price school lunches. To assess the plausibility of these findings, I investigate the additional calories consumed by those in the school lunch program. Using food recall data, I find that children who eat school lunch consume 40-120 more calories at lunch than those who brown bag, but that both groups of children consume the same amount of calories the rest of the day (not including lunch). I estimate that for children an extra 40-120 calories per day would increase the incidence of overweight by 2 to 4 percentile points - the same as the observed increase in overweight. I estimate that if school lunches were made healthier and consistently met the nutrition requirements set for them, the childhood obesity rate would decline.

Many thanks go to Kristin Butcher, David Card, John Cawley, Dan Eisenberg, Art Goldsmith, Hilary Hoynes, Sarah Reber and seminar participants at the University of Chicago, University of Illinois, Federal Reserve Bank of Chicago, Princeton, and especially the annual meeting of the Scholars in Health Policy Research meeting for helpful comments. Generous financial support from the Robert Wood Johnson Foundation and the Center for Human Potential and Public Policy is gratefully acknowledged. 


\section{Introduction}

Obesity is a pressing national health problem. Recent statistics indicate that 30 percent of adults are obese, and another 30 percent are overweight. Sixteen percent of 611 year olds are obese - up from 4 percent in the mid-1970s. ${ }^{1}$ The causes of the recent surge in obesity are not well understood, and there are few policy interventions that have been able to reduce obesity. In The Surgeon General's Call to Action to Prevent and Decrease Overweight and Obesity (2001), schools are identified as a key setting for public health strategies to promote healthy eating and combat obesity.

The National School Lunch Program (NSLP) serves lunch to almost 30 million students -60 percent of the total student population. Almost all public schools offer the NSLP. Although a large fraction of school lunch participants get their lunch free (48 percent) or at a reduced price ( 9 percent), a substantial number ( 43 percent) are from nonpoor families and pay full price. As a result, if school lunches are contributing to childhood overweight, making lunches healthier could potentially impact a large number of children across socio-economic status, race, and geography boundaries.

The government plays a large role in the school lunch program, providing $\$ 6.1$ billion in total cash payments to local schools. ${ }^{2}$ In addition, the government provides another 15.75 cents per lunch served in surplus food commodities such as fruit juices and peanut butter. Although the government's bankrolling of the program might suggest that they are able to influence what is served as part of school lunches, they seem to not leverage that influence effectively to date. For example, in 1995 new guidelines were

\footnotetext{
${ }^{1}$ Child obesity is defined as a body mass index (BMI, the ratio of weight in $\mathrm{kg}$ to height in meters squared) that surpasses the $95^{\text {th }}$ percentile of a fixed distribution for a child's age and gender. For elementary school students, the cutoff is around a BMI of 20.

${ }^{2}$ For comparison, Title I provided $\$ 9.8$ billion in 2002. In 2003, the government reimbursed schools $\$ 2.14$ for every free lunch served, $\$ 1.74$ for each reduced price lunch, and $\$ 0.20$ for each full price lunch.
} 
instituted for healthier school lunches, but even today few schools actually meet those goals.

In this paper, I show that school lunch eaters consume more calories at lunch but not at other times of the day - than brown baggers. These additional calories could lead to a 2-4 percentage point higher obesity rate among school lunch eaters.

Furthermore my results show that, holding all else constant, there was no difference between school lunch eaters and brown baggers when they entered kindergarten, before they were exposed to school lunches. After they have been in school for a couple of years, though, school lunch eaters do experience higher obesity rates than brown baggers. If school lunches were made healthier, a significant decline in childhood obesity would likely occur.

\section{History, Previous Research and Policy Context}

Economists have relatively recently come to be interested in the study of obesity and overweight. In a recent paper, Cutler, Glaeser and Shapiro (2003) study the doubling of obesity rates among adults over the past 20 years. They estimate that the increase in obesity can be accounted for by a calorie imbalance of 100 to 150 calories per day, and find that the recent increase is likely due to eating more calories (opposed to burning fewer calories through activity). ${ }^{3}$ Comparing recent food diaries to those collected in the early 1980 s, they find that the increase in calorie intake appears to come from the consumption of more meals and snacks per day, and not from "super-sizing" - that is, eating a larger number of calories per meal.

\footnotetext{
${ }^{3}$ Lakdawalla and Philipson, 2002, find that much of the increase in body weight over the past century is due to decreased physical activity - largely from workers moving away from physically demanding jobs and toward sedentary ones.
} 
Even less work has been done by economists to examine overweight among children. Anderson, Butcher and Levine (2003) use the National Longitudinal Survey of Youth to follow children over time, and measure the effects of increased maternal employment rates over the past 30 years - including all the attendant changes in children's lives that come when mothers become employed, such as eating more preprepared meals and potentially playing outside less. Altogether, increased maternal employment can only explain less than one percentage point of the 9 percentage point increase in overweight. Anderson and Butcher (2005) investigate the impact of vending machines and find that a 10 percentage point increase in access to vending machines is associated with a 2.2 percentage point increase in the body mass index of students who have overweight parents. ${ }^{4}$

The role of schools in addressing children's overweight has gotten increased policy attention. In 1995, after research showed that many school lunches failed to meet nutrition requirements, Congress passed the "School Meals Initiative for Healthy Children." The new policy required food served to meet one-third of the child recommended daily allowance (RDA) of calories, protein, calcium, iron, and vitamins A and $\mathrm{C}$, and for no more than 30 percent of calories to come from fat. ${ }^{5}$ In addition, schools were to restrict foods of "minimal nutritional value" such as soda. In a subsequent survey, two-thirds of cafeteria planners reported that the new guidelines had at least somewhat changed their school menus. ${ }^{6}$

\footnotetext{
${ }^{4}$ Vending machines are much more prevalent in high schools. Over 60 percent of high schools have vending machines, while only 11 percent of elementary schools do.

${ }^{5}$ Saturated fat was to account for fewer than 12 percent of calories.

${ }^{6}$ By my calculations of the SNDA-2, fewer than 4 percent of schools meet all of the guidelines outlined in the Healthy Children Initiative.
} 
School districts around the country have also responded to the obesity epidemic. New York City received considerable press attention when they announced they were mounting an "aggressive" campaign to make school lunches healthier, developing healthier recipes for some favorite foods, banning beef ravioli and potato salad altogether, and removing soda and candy from vending machines. In essence, their campaign will serve to meet the 1995 lunch standards by 2008. Oakland, California was the first major school district to ban junk food in vending machines in January, 2002, which cost them an estimated $\$ 650,000$ in lost revenues annually. Many other school districts have jumped on the bandwagon; on June 23, 2004, Chicago Public Schools banned vending machines in elementary and middle schools, and imposed a requirement that snacks sold in vending machines in high schools meet reasonably stringent nutritional standards. Focusing on calories burned instead of calories eaten, Texas recently toughened their gym requirement. In 1995, in an effort to strengthen academic achievement, elementary school students were no longer required to take gym class daily, but the state school board reversed itself in 2001, requiring at least 135 minutes of gym per week in order to "combat childhood obesity, heart disease and diabetes."

Predecessors to the National School Lunch program date back to the Great Depression, when the government began to distribute surplus farm commodities to schools with large populations of malnourished students. By the 1940s, the Federal government also began cash transfers for equipment and staff. In 1946 Congress passed the National School Lunch Act (Gunderson, 1971). The act's statement of purpose indicates that a nonprofit school lunch program should be established "as a measure of national security" with the dual purposes "to safeguard the health and well-being of the 
Nation's children and to encourage the domestic consumption of nutritious agricultural commodities and other food..." The number of students participating in the NSLP has grown from 7.1 million in 1946 to 28.4 million in 2003, and the USDA estimates that 187 billion lunches have been served under the program.

To date, most research on the National School Lunch Program has been focused on how the program impacts intake of calories and various nutrients. Most research has found that NSLP participants consume more vitamins and minerals at lunch than nonparticipants, and that the 24-hour effect is smaller but still statistically significant (Fraker 1987; Devaney et al. 1995; Gleason and Suitor 2001, 2003). ${ }^{7}$ Gleason and Suitor (2001) also find that NSLP participants consume more calories in a typical day than nonparticipants, but that all the additional calories come at lunch time. As public health priorities are shifting from combating malnutrition to addressing the epidemic of childhood obesity, it seems worthwhile to investigate the potential of the NSLP to contribute to childhood obesity. ${ }^{8}$

\section{Measuring the Impact of School Lunches}

Students who eat school lunches are more likely to be overweight than their classmates who brown bag their lunch. But, as mentioned above, this correlation could reflect other characteristics that influence both the probability of being obese and the probability of eating school lunch, since of course children are not randomly assigned into school lunch and brown bag treatments. There are all sorts of observable and

\footnotetext{
${ }^{7}$ An important recent paper by Bhattacharya et al. (2004) finds that the National School Breakfast Program improves the nutritional quality of food consumed, but does not increase the number of calories consumed.

${ }^{8}$ An interesting paper by Figlio and Winicki (2005) finds that Virginia schools facing accountability sanctions increase the caloric content of their school lunches during test week by over 100 calories per day, in a probable attempt to boost students' short-term cognitive performance.
} 
unobservable factors that predict the likelihood that a child will eat a school lunch - for example, low-income, African American and Hispanic children are more likely to eat school lunch. Unfortunately, many of these same observable and unobservable factors are also associated with being overweight, so a naïve regression of school lunch on overweight may overstate the causal impact of lunch if not all other related factors are perfectly controlled. As described below, I take several steps to address this, including looking at changes in obesity over time and using a regression-discontinuity approach. These approaches suggest that, all else equal, children who eat school lunches are about 2 percentage points more likely to be overweight than brown baggers. I then show dietary recall data that indicates that children who eat school lunches consume an extra 60 or so calories per day, and that a calorie increase of this magnitude is large enough to cause the observed obesity increase.

\section{Changes over time}

One way to isolate the effect of school lunches is to follow a cohort of children over time starting at school entry. If children who eat different types of lunches enter school with similar levels of obesity, but after a few years end up with different obesity rates by school lunch type, this may indicate that school lunches contribute directly to obesity. Fortunately, there is a dataset available that allows such a comparison to be made. The Early Childhood Longitudinal Study - Kindergarten Cohort (ECLS-K) is a panel data following children from kindergarten through first grade, collected by the US Department of Education. ${ }^{9}$ The dataset covers approximately 15,000 students in 1000

\footnotetext{
${ }^{9}$ The latest panel - following the same children through $3^{\text {rd }}$ grade - recently became available, but I have not included updated information in this version of the paper.
} 
different schools and collected a wide range of information on children, their families and their schools. In addition, children's heights and weights were directly measured by the survey collectors at the beginning and end of kindergarten, and at the end of first grade. ${ }^{10}$

I limit the analysis in this section to only white students who are ineligible for free or reduced-price lunch (who attend schools that participate in the school lunch program). As a result, as shown in Table 1, students who brown bag their lunches look quite similar along many dimensions compared to those who eat school lunches. Tables 1 and 2 compare students by lunch type conditional on school fixed effects interacted with mother's labor force status (that is, whether she is in the labor force - including employed, unemployed and working part time - or not). As a result, the differences are measured between school lunch eaters and brown baggers in the same school who have mothers in the same employment category. As shown in Table 1, brown baggers and school lunch eaters have parents with similar education levels, have similar test scores, and had similar weights both at birth and at kindergarten entry. There are some differences, though: brown baggers come from slightly larger families and have slightly larger numbers of children's books in their homes, while school lunch eaters were more likely to have been in day care before kindergarten (even conditional on mothers' employment status). While I control directly for all of these characteristics in the results that follow, if there are also unobservable differences between the groups that impact the trajectory of obesity, then the effect of school lunches will be biased. ${ }^{11}$ I examine several potential sources of bias in the tables that follow, and conclude that the impact of school lunches on obesity is robust.

\footnotetext{
${ }^{10}$ Data were collected on a subset of the respondents at the beginning of $1^{\text {st }}$ grade as well.

${ }^{11}$ Since the children have similar levels of overweight at kindergarten entry, the unobservable characteristics would have to impact the change in overweight and not the level.
} 
Table 2 shows regression-adjusted results. The dependent variable is equal to one if the child's body mass index (BMI) is above an age- and gender-specific threshold. ${ }^{12}$ As shown in columns (1) - (4), at kindergarten entry, the type of school lunch that children will go on to eat in kindergarten and first grade is not associated with any differences in obesity rates, whether or not covariates are controlled. This suggests that any unobservable differences between brown baggers and NSLP participants have not materialized into obesity differences by kindergarten entry. By the end of first grade, however, school lunch eaters are 2.4 percentage points more likely to be overweight, controlling for observable characteristics and school-by-mother's-employment fixed effects. When baseline obesity is included as an explanatory variable, the difference in obesity rates edges down to about 2 percentage points. In either case, after two years of exposure to school lunches children are 2 percentage points (on a base of 9 percent) more likely to be overweight than their classmates who brown bag their lunch.

\section{Specification checks}

A major cause of concern in interpreting these results is that even though brown baggers and lunch eaters come into school with the same rates of overweight, there might be other changes in the child's family that would contribute to overweight and be correlated with lunch status. These explanations typically fall into two categories: 1) changes that occur at the same time as school enrollment that impact a child's food and activity environment (differentially by school lunch status) and 2) underlying differences

\footnotetext{
${ }^{12}$ The threshold was set as the $95^{\text {th }}$ percentile of the age- and gender-specific BMI distribution of a nationally representative group of children in the early 1970s, and is the standard measure for obesity in children aged 2-18. BMI is calculated as a child's weight in kilograms divided by its squared height, in meters.
} 
between brown bag and school lunch families that are not measurable until a child is slightly older. For example, if a mother returns to work when her child enters kindergarten and no longer has time to prepare healthy meals (including a brown bagged lunch), this may contribute to a child becoming overweight in kindergarten and first grade. Other, harder to measure differences may creep in around the same time and be correlated with lunch status. For example, parents who care more about health may be more likely to enroll their children in after-school sports and brown bag their lunches, but since after-school and club sports usually begin in kindergarten or first grade, the impact they have on reducing overweight may not kick in until after kindergarten enrollment.

Table 3 presents some robustness checks that attempt to address family-level changes that coincide with kindergarten enrollment. In about 10 percent of the sample, mothers enter employment after their children enter kindergarten, which may shift home health production that is correlated with school lunch status but not caused by it. Columns (1) - (6) limit the sample to children whose mothers did not change employment status between their child's entry into kindergarten and the end of first grade; the impact of school lunch on obesity remains about the same at 2 percentage points.

Another potential measure exploits the presence of older and younger siblings, since the home meal preparation and activity environment may be more stable if the kindergarten entrant is not the first child to enter school and is not the last child to enter school. Columns (7) - (12) show that the pattern continues to hold among arguably more stable home environments: there is no difference in obesity rate at kindergarten entry, but by the end of first grade a gap opens up. 
In order to attempt to measure other differences in unobservable characteristics between lunch buyers and brown baggers, I compared responses to questions about family inputs and child activities. Along a host of variables intended to proxy for a "high quality" home environment (such as trips to museums, whether a parent reads to the child, TV viewing habits), there was no difference between lunch buyer and brown bagger families.

Another potential robustness check compares students who attend full- and halfday kindergarten. If school lunches were causing an increase in obesity, then the gap between school lunch buyers and brown baggers should not open up until first grade for half-day kindergarten students. In Table 4, students who eat school lunch in first grade are compared to their schoolmates at the end of kindergarten. School lunch eaters who are exposed to school lunch in kindergarten (i.e. have full-day kindergarten) are more likely than their schoolmates to be obese. Students who are not exposed to school lunch in kindergarten show no difference in obesity rate by first grade school-lunch status (see column 2). By the end of first grade, obesity rates have opened up between school lunch buyers and brown baggers in both types of schools.

The effect is also robust to alternate dependent variables, as shown in Table 5. Measuring BMI directly, or $\log (\mathrm{BMI})$ produces qualitatively similar results. Redefining the outcome of interest from "obese" to "at risk of obesity," which is defined as the $85^{\text {th }}$ percentile of a fixed distribution of body mass index conditional on age and gender, shows similar results. Limiting the sample only to obesity "movers" - that is, only including those who move from overweight in kindergarten to non-overweight by the end 
of first grade, and vice versa - reveals that school lunch eaters are much more likely to move into overweight (see columns 7-8). ${ }^{13}$

A random subset of students was surveyed at the beginning of first grade, giving me the opportunity to investigate whether school lunch status has an impact on weight gain (or loss) over the summer. I find that - conditional on obesity at the end of kindergarten - school lunch status does not predict change in weight over the summer.

Up to this point, we have concentrated on the impact of additional calories consumed on obesity. But a person's weight is a function of calorie intake and calorie outflow, and it may be the case that children who brown bag their lunches are for some reason more active and that is the cause of the weight disparity. Since all results have been estimated conditional on school fixed effects, we would not expect differences in school-time physical activity to be driving the results - for example, all students are subject to the same physical education requirements, regardless of school lunch status. But there may be important differences in non-school activity levels that are correlated with lunch status. The ECLS data collected limited information about after-school activities such as participation in sports and dance, and also parental assessment of a child's activity level and amount of weekly aerobic activity. While measures of activity are directly related to overweight (for example, children who are "less active than other children" are 13 points more likely to be overweight), these activity measures are not related to a child's school lunch status. ${ }^{14}$ One drawback of these measures is that they are measured at the end of kindergarten and not at baseline.

\footnotetext{
${ }^{13}$ I also tested to make sure that there was no difference, on average, in the height or age of children by school lunch status.

${ }^{14}$ Other measures of parental inputs - such as trips to the museum - do not differ by lunch status, either.
} 


\section{Regression discontinuity approach}

Another approach to isolating the causal impact of school lunches on obesity is to leverage the (theoretically) sharp eligibility cutoff for school lunch subsidies. By the rules of the program, if a student's family earns less than 130 percent of the Federal Poverty Line (FPL) the student is entitled to receive school lunch without cost. Students with incomes between 130 percent and 185 percent of the FPL are eligible for a reduced price lunch. The reduced-price charged varies by school, but the average price charged is 40 cents. Above 185 percent of the poverty limit the price reverts to "full" price, on average $\$ 1.75$ per lunch. This means that students at 184 percent of the poverty limit face a dramatically different price for lunch than students at 186 percent of the poverty limit. This large difference in lunch prices faced by students who have similar levels of family income suggests a regression-discontinuity (RD) design (see for example Hahn, Todd and van der Klaauw 2001; Lee 2005; DiNardo and Lee 2004; McCrary and Royer 2004; Angrist and Lavy 1999; Matsudaira 2004).

To clarify the proposed framework, suppose that the relationship between a child's weight and school lunch eating can be modeled using a constant treatment effects model:

$$
y_{i}=D_{i} \theta+f\left(R_{i}\right)+v_{i}
$$

where $y_{i}$ is a measure of the student's obesity status, $D_{i}$ is an indicator variable for whether the student eats school lunch, $R_{i}$ is the student's family income measured as income-to-poverty ratio, and $v_{i}$ is a vector of other covariates that influence child obesity. The key to the approach is that students are discontinuously likely to participate in the school lunch program as their family income moves above the subsidy threshold, $R^{0}$, of 
185 percent of the FPL. This case is often called a "fuzzy" regression discontinuity, because the probability of treatment varies discontinuously around rule, but the rule is not deterministic (i.e. not all children below the cutoff are forced to eat a school lunch, and those above the cutoff are allowed to eat a school lunch). The treatment in this case is a price reduction, but students ineligible for the subsidy may still purchase the exact same lunch for a higher price. The impact of the subsidy rule on lunch participation is therefore given by

$$
\gamma=\lim _{R \uparrow 0} E\left[D_{i} \mid R_{i}=R^{0}\right]-\lim _{R \downarrow 0} E\left[D_{i} \mid R_{i}=R^{0}\right] .
$$

Similarly, the impact of the lunch subsidy on a child's obesity status is given as

$$
\varphi=\lim _{R \uparrow 0} E\left[y_{i} \mid R_{i}=R^{0}\right]-\lim _{R \downarrow 0} E\left[y_{i} \mid R_{i}=R^{0}\right] .
$$

Therefore, in order to uncover the estimated impact of school lunch on obesity rates, one must "scale up" the impact on obesity by the change in lunch eating rates around the subsidy cutoff using the Wald estimator $\theta=\varphi / \gamma$.

To implement this approach, I regress various dependent variables on a $4^{\text {th }}$ order polynomial in $R_{i}$, an indicator variable $S_{i}$ for whether the child is income-eligible for the lunch subsidy (i.e. $R_{i}<R^{0}$ ), and all interaction terms between $S_{i}$ and the polynomial in $R_{i}{ }^{15}$ Results are shown in Table 6, and graphically in Figure 1. Using the RD approach, students eligible for a school lunch subsidy are 4 percentage points more likely to be obese than students just on the other side of the cutoff. For a sense of the magnitude of this finding, column (3) displays the mean obesity rate of children near the cutoff; lunch eaters are almost one-third more likely to be obese. Using $\log (\mathrm{BMI})$ as the dependent variable, the impact of school lunches is about a 2 percent increase in weight. In panel B,

\footnotetext{
${ }^{15}$ The results are similar if higher-order terms of $\mathrm{R}$ are included and if other covariates are controlled.
} 
results are shown for the discontinuity in school lunch participation. Income-eligible students are much more likely to report receiving the lunch subsidy, but only 4 percentage points more likely to report eating a school lunch. The lunch-eating rate among low income students is universally very high, with 82 percent of students from families with incomes just above the threshold participating in the school lunch program. There is a statistically significant discontinuity at the lunch cutoff in both lunch eating and in weight measures. As described above, to account for the "fuzzy" nature of this discontinuity, the program impact is measured as the ratio of the impact on weight outcomes to the increase in lunch participation. While the point estimate of the impact is too large to be credible, the standard errors are sizeable. Overall, this supports the evidence presented earlier that school lunches have a causal impact on students' obesity rate, even though the RD approach is identified off of a very different part of the income distribution.

The identification strategy employed here hinges on the notion that once the impact of income is controlled in a smooth manner, the remaining discontinuity in variables located at the lunch subsidy threshold is caused by the lunch subsidy. If families that particularly value the school lunch subsidy can alter their incomes (or reported incomes) to fall just below the threshold, though, the strategy would be invalid. To test the validity of the approach, I present several pieces of evidence that there is no obvious sorting into the subsidy around the neighborhood of the threshold.

As a test of the RD design, Panel $\mathrm{C}$ repeats the exercise for several predetermined variables. Figure 2 displays these results graphically. If the design is legitimate, none of the pre-determined characteristics should be discontinuous around the 
threshold. On the other hand, if certain types of families were more likely to fall just below the cutoff then there may be something else causing the discontinuity the income level equal to 185 percent of the FPL, such as sorting into the program or other programs with the same income eligibility cutoff. For example, some Medicaid/SCHIP programs have eligibility cutoffs at 185 percent of the poverty line, and one may be concerned that this approach may be picking up the effect of those other programs. ${ }^{16}$ As shown in Panel $\mathrm{C}$, there is no measured discontinuity at the subsidy cutoff along a wide variety of measures: race, test scores, family structure, or reported insurance status. Importantly, there is also no difference in baseline (i.e. Kindergarten entry) obesity and weight, suggesting that the treatment identified in the RD approach is administered after school entry.

Column (4) reports another specification check. This shows results from a falsification exercise, using a fictional cutoff threshold of 200 percent of the FPL. There are no observed discontinuities in weight measures or lunch-eating measures, or on predetermined characteristics, when this fictional cutoff is used. ${ }^{17}$

Another test of the approach's validity is whether the density of $R$ is discontinuous around the subsidy threshold, which might indicate self-selection to below the cutoff. There is some evidence in other studies that children from income-ineligible families receive the subsidy at surprisingly high rates - possibly as a result of families purposely under-reporting their income in order to qualify under lax eligibility rules. To

\footnotetext{
${ }^{16}$ Only a few states use 185 percent of the poverty line as the income cutoff for insurance for children in the ECLS cohort. States with 185 percent cutoff lines for 7 year olds in the year 2000 are: CO, IL, IA, NE, OK, VA, WI.

${ }^{17}$ There is a small discontinuity in percent reporting getting subsidized lunches, but that does not translate into a difference in reported rates of eating lunches. Results of this falsification exercise are similar for fictional thresholds of $150 \%$ and $230 \%$ of FPL.
} 
qualify for the lunch subsidy, parents report their income and family size (or their TANF or food stamp case number) to their school at the beginning of the year. No documentation of income is required, though a random subset of eligibles are selected to provide follow-up at a later time in the school year (Burghardt et al., 2004). A recent Department of Agriculture report (FNS, 2003) found that after children receiving subsidies provided income verification, almost 20 percent were receiving a subsidy more generous than their eligibility implied. ${ }^{18}$ The potential for this to be a problem in the data used here is smaller, since incomes are being reported to an independent survey and there is little incentive to tweak one's income level to appear eligible for any programs. In fact, $34 \%$ of students with reported income between $185-230 \%$ of the FPL report receiving a subsidized lunch. ${ }^{19}$ As shown in Appendix Figure 1, there is no apparent discontinuity in the income distribution around the subsidy threshold. ${ }^{20}$

\section{Is the Impact Plausible?}

The overall finding is that children who eat a National School Lunch Program lunch for two school years are about 2 percentage points more likely to be obese. In this section, I provide evidence that this is a plausible magnitude. On average, students eating

\footnotetext{
${ }^{18}$ This could be because of inaccurate reporting when they qualified for lunches, or could represent variation in income over the school year between when they originally qualified and when the follow-up was done.

${ }^{19}$ It is worth noting that the income distribution is slightly lumpy, because most family incomes are reported in round thousands.

${ }^{20}$ Another promising RD approach that did not pan out was to look for a similar discontinuity between the free-lunch and reduced-price lunch threshold, at 130 percent of the poverty line. Unfortunately, the data do not distinguish free lunch from reduced price lunch, so I could not directly test whether students discontinuously report receiving free lunch below that threshold. Nonetheless, lunch consumption is reported but there was no observable change in reported participation in the lunch program around that threshold, despite the theoretically sharp change in price charged. This lack of finding could be caused by noise in income measures around that cutoff, near universal lunch participation (93 percent of students just above 130 percent family income report eating lunch), or program errors that make the cutoff less sharp. Just as there is no discontinuity in lunch eating at the free-lunch threshold, there is also no jump in obesity rates or child weight there.
} 
a school lunch consume an extra 40 calories per day - all at lunch - and holding all else constant, that increase could account for the observed weight gain.

\section{Measuring Calories in School Lunches}

In order to measure the difference in average calories consumed by brown baggers and school lunch eaters, investigate two food recall surveys. Using such data is often problematic because food consumption is notoriously underreported. ${ }^{21}$

Furthermore, the very act of recording it is known to alter one's food intake. These problems may be attenuated in this case because I am measuring the difference in calories. If calories are underreported by the same amount by both groups of children, for example, the difference in calories would still be accurate. ${ }^{22}$

Table 6 presents regression results from the NHANES III, a nationally representative dataset collected by the Centers for Disease Control in 1988-94, where the first dependent variable is the number of calories consumed at lunch, and the second is all non-lunch calories consumed. The sample is limited to weekdays not during the summer. ${ }^{23}$ Students report - and I use as the school lunch variable - whether they eat school lunch "every day" or "most days;" there is no direct information about whether they ate the school lunch on the particular days that the food diary was collected. In addition, defining what is "lunch" is non-trivial, so I take several approaches. The food diaries collect information on what is eaten, when, where, and how the eater would

\footnotetext{
${ }^{21}$ For example, Cutler et al. (2003) simulate that if American men were really consuming the number of calories reported in NHANES food diaries, they would have an average weight of a mere 108 pounds.

${ }^{22}$ It is possible that school lunches are more accurately reported if, for example, the family has a school lunch menu that they use as an aid when reporting the child's intake. On the other hand, if a parent packed the child's brown bag lunch then they may have a similarly good recollection of the child's intake.

${ }^{23}$ There is no direct measure of whether the diary day is a "school day," though the location of the consumption (e.g. "at school") is reported.
} 
categorize it (e.g. breakfast, snack, etc.). One measure of "lunch," of course, is everything eaten that the respondent categorizes as "lunch." One problem arises with this definition because there are multiple words in Spanish for lunch - some children report the noontime meal as "almuerzo" while others report it as "comida." Unfortunately, "comida" can also be used to describe other meals, so a definition that incorporates these three categories (lunch, almuerzo and comida) as "lunch" will also contain an evening meal in many cases. To address this problem, one can instead define "lunch" as anything eaten around noontime, regardless of the name of the meal. It turns out that because of tight school and cafeteria schedules, some students eat lunch as early as $10 \mathrm{AM}^{24}$ As a result, defining "lunch" as anything eaten between 10 AM (after breakfast, but early enough to catch early lunch times) and 1:30 PM (before after-school snacks, but late enough for late lunch shifts) appears to be a reasonable definition, and is my preferred method. $^{25}$

As shown in Table 7, students in the NHANES who eat a school lunch daily appear to consume 46 more calories at lunch than those who regularly brown bag their lunch, but consume the same number of calories at other times of the day. That is, controlling for observable characteristics such as age, race, gender, parents' BMI and family size, school lunch eaters consume about 46 extra calories per day, but this additional consumption comes entirely at lunch.

\footnotetext{
${ }^{24}$ Many of the students who eat lunch early in the day (reasonably!) report the meal as a "snack" and report eating "lunch" either after school is over or not at all, so the category-based definition of lunch would have excluded these students' participation in the school lunch program.

${ }^{25}$ Another method that seems reasonable at first glance is to separate all food consumed at "school" and at "non-school", but this inadvertently includes school breakfasts and any after-school snacks eaten at school during after-school programs or sports events.
} 
This finding is supported by research by Gleason and Suitor (2001) with Mathematica Policy Research (MPR) using the Continuing Survey of Food Intake by Individuals (CSFII), a nationally representative survey collected by the USDA. MPR finds that school lunch participants consume substantially more calories than their brownbagger counterparts - an extra 120 calories per day, after controlling for demographic characteristics. They also find that all of these additional calories come at lunchtime and that there is no difference in the non-lunch calories consumed by the two groups.

One reason for the wide range in the estimated additional calories consumed might be due to the different approaches to measuring children's food intake taken by each dataset. In the NHANES, children under age 12 were interviewed in the presence of a parent so that the parent could assist the child's recall. The CSFII, on the other hand, was particularly geared toward estimating the amount of plate waste; as a result, children were interviewed without their parents so they would be more likely to be honest about which foods they actually ate and which ones they traded or discarded. The difference in magnitude could be explained if, for example, brown bag children discard more of their unwanted food items, while NSLP children may not to discard their food by choice or might be more closely monitored and encouraged to eat what was served. Although the Suitor and Gleason study and my analysis of the NHANES include different choices about how to define lunch and which variables to control, both results appear to be reasonable. School lunch participants probably consume between 40 and 120 more calories per day than brown baggers do, and all of the difference comes from eating a larger lunch. ${ }^{26}$

\footnotetext{
${ }^{26}$ It is worth noting that this does not imply that brown baggers themselves eat a "healthy" lunch, just that they eat fewer calories than NSLP participants. The number of calories consumed does not indicate
} 


\section{Measuring the Potential Effect of Additional Calories}

Are as few as 40 extra calories per day enough to cause a measurable difference in obesity rates in children? Following the approach in Shofield (1985), I simulate the potential impacts of additional calories for first graders, based on the following equation ${ }^{27}$ :

$$
\mathrm{K}=\mathrm{a}+(\mathrm{B}+\mathrm{E}) * \mathrm{~W}+0.1 \mathrm{~K}
$$

where $K$ is caloric intake in kilocalories, and $W$ is weight in kilograms. The constants $a$ and $B$ represent the Basal Metabolic Rate for females and males ages 3-10, and vary only by gender in the current simulation. $E$ is the energy expenditure constant, which represents the amount of physical activity the children engage in; calories burned through physical activity depend both on $E$ and on the child's weight. ${ }^{28}$ The final term in the equation represents the thermic effect of food - that is, the calories burned from eating and digesting food.

Results from the simulation are presented in Table 8. If first graders consume just an additional 40 calories, then the rate of overweight increases by 1.7 percentage points. As a result, we could expect to observe school lunch eaters' obesity rates to be about 2 percentage points higher than brown baggers' rates, all else equal. If the number of additional calories in a school lunch is closer to 120 as Gleason and Suitor suggest, the difference in obesity rates could be as high as 7 percentage points. In either case, the

whether the food packed is largely prepackaged - such as "Lunchables," potato chips, or yogurt laced with added sweeteners and unnatural coloring - or is a homemade sandwich and fruit. In future work, I hope to investigate how the composition of brown bag lunches has changed over time and whether that can account for any of the large increase in children's overweight.

${ }^{27}$ This is similar to the simulations in Cutler, Glaeser and Shapiro (2003.)

${ }^{28}$ In the simulation, I hold constant the amount of physical activity when more calories and weight are added. In reality, children may be less active if they weigh more, and this method would therefore understate the increase in obesity from extra calories. 
seemingly small difference in calories - if consumed every day - could lead to a measurable increase in overweight. ${ }^{29}$

\section{Potential Impacts on Hunger}

It appears that school lunches increase the probability that a child is overweight by about 2 percentage points, and this suggests the relatively straightforward policy intervention of making school lunches healthier. But since the school lunch program's mission (at least historically) is primarily to combat hunger, it is important to also consider the potential impact of any policy changes on the underfed. For example, reducing calories served by 40 across the board increases the simulated rate of underweight by 0.5 percentage points - from 1.4 to 1.9 .

One potential method to address underweight is through the school breakfast program. Fifteen percent of children who are underweight and from low-income families attend schools that do not offer the school breakfast program, even though they participate in the school lunch program. In addition, underweight students who do attend schools with a breakfast program are less likely to participate in the program than their classmates who are not underweight. Encouraging eligible students to enroll in the school breakfast program could offset any increase in underweight associated with reducing calories in school lunches.

It also appears to be the case that - as shown in Table 9 - schools with a higher fraction of low-income students already serve healthier lunches. ${ }^{30}$ On average, schools

\footnotetext{
${ }^{29}$ To put the calorie increase in context, a can of cola has about 145 calories and a "fun size" Snickers candy bar has about 70 calories.
} 
with the lowest percent of low-income students serve lunches with about 80 more calories than schools with the highest percent of low-income students. Other nutrition measures - such as meeting the standards for iron, calcium and vitamins, or keeping the percentage of calories from fat below 30 percent - are either flat or improve as the fraction of low-income students increases. This implies that an intervention in favor of healthier lunches should likely be targeted at higher-income schools, which are less likely to have students suffering hunger.

\section{Conclusions}

When compared to their classmates who brown bag their lunches, school lunch participants are 2 percentage points more likely to be overweight - all else equal. Analysis of food diary data suggests that school lunch eaters consume between 40 and 120 calories more at lunch than brown baggers, but both groups consume the same number of calories the rest of the day. A simulation of the relationship between weight and caloric intake among children indicates that as few as 40 additional calories per day could lead to a 2 percentage point difference in obesity rates. Although this explains a relatively small part of the overall obesity rate, and is not a strong candidate for describing the cause of the large and rapid increase in the rate, it suggests a relatively straightforward policy intervention and - since the Federal government spends over $\$ 6$ billion per year on the program - one in which the government wields considerable leverage.

\footnotetext{
${ }^{30}$ The underlying data in this table come from the SNDA-II, a survey of school and district food services with a sample size of about 1700 . Note that even though low-income students are more likely to be obese, this does not appear to be caused by school lunches.
} 


\section{References}

Anderson and Butcher (2004). "Reading, Writing and Raisinettes: Are School Finances Contributing to Children's Obesity?" Federal Reserve Bank of Chicago Working Paper Number 16.

Anderson, Butcher and Levine (2003). "Maternal Employment and Overweight Children," Journal of Health Economics, 22:477-504.

Angrist, Joshua and Victor Lavy (1998). "Using Maimondies' Rule to Estimate the Effect of Class Size on Scholastic Achievement," Quarterly Journal of Economics 114, pp. 533-75.

Bhattacharya, Jayanta, Janet Currie, and Steven Haider (2004). "Breakfast of Champions? The School Breakfast Program and the Nutrition of Children and Families," NBER Working Paper 10608, June.

Burghardt, John, Philip Gleason, Michael Sinclair, Rhoda Cohen, Lara Hulsey and Julita Milliner-Waddell (2004). "Evaluation of the National School Lunch Program Application/Verification Pilot Projects," Special Nutrition Program Report Series, No. CN-04-AV1, FNS, USDA.

Cutler, Glaeser and Shapiro (2003). "Why Have Americans Become More Obese?" Journal of Economic Perspectives 17:93-118.

Devaney, Barbara, A. Gordon and J. Burghardt (1995). "Dietary Intakes of Students," American Journal of Clinical Nutrition, 61, pp. 205S-212S.

DiNardo, John and David S. Lee (2004). "Economic Impacts of Unionization on Private Sector Employers: 1984-2001,” NBER Working Paper \#10598.

Figlio, David and Joshua Winicki (2005). "Food for Thought: The Effects of School Accountability Plans on School Nutrition," Journal of Public Economics, 89:2-3 (February), pp. 381-94.

Food and Nutrition Service (2003). "School Food Authority Administration of National School Lunch Program Free and Reduced Price Eligibility Determination," Special Nutrition Program Report Series, No. CN-03-AV, FNS, USDA.

Fraker, T. (1987). The Sodium and Macronutrient Content of USDA School Lunches. USDA Food and Nutrition Service Report.

Gleason, Phil and Carol Suitor (2001). Children's Diets in the Mid-1990s: Dietary Intake and Its Relationship with School Meal Participation. USDA Food and Nutrition Service, Report Number CN-01-CD1, January. 
Gleason, Philip and Carol W. Suitor (2003). "Eating at School: How the National School Lunch Program Affects Children's Diets," American Journal of Agricultural Economics, 85:4 (November), pp. 1047-1061.

Gunderson, Gordon W. (1971). The National School Lunch Program: Background and Development. Washington, DC: United States Department of Agriculture.

Hahn, Jinyong, Petra Todd and Wilbert Van der Klaauw (2001). "Identification and Estimation of Treatment Effects with a Regression-Discontinuity Design," Econometrica 69(1), pp. 201-209.

Institute of Medicine of the National Academies (2005). Preventing Childhood Obesity: Health in the Balance. Washington, DC: The National Academies Press.

Lakdawalla and Philipson (2002). "The Growth of Obesity and Technological Change: A Theoretical and Empirical Examination,” NBER Working Paper 8946.

Lee, David (2005). "Randomized Experiments from Non-random Selection in U.S. House Elections," forthcoming, Journal of Econometrics.

Matsudaira, Jordan D. (2004). "Sinking or Swimming? Evaluating the Impact of English Immersion versus Bilingual Education on Student Achievement," mimeo, University of Michigan.

McCrary, Justin and Heather Royer (2005). "The Effect of Maternal Education on Fertility and Infant Health: Evidence from School Entry Policies Using Exact Date of Birth," mimeo, University of Michigan.

Schofield, Schofield and James (1985). "Basal Metabolic Rate: Review and Prediction Together with Annotated Bibliography of Source Material." Human Nutrition: Clinical Nutrition 39C, Supplement 1, 5-96.

U.S. Department of Health and Human Services (2001). The Surgeon General's call to action to prevent and decrease overweight and obesity. Rockville, MD: U.S. Department of Health and Human Services, Public Health Service, Office of the Surgeon General. 
Table 1: Characteristics at Kindergarten Entry

\begin{tabular}{|c|c|c|c|}
\hline & \multicolumn{3}{|c|}{ All White, Non-Poor } \\
\hline & $\begin{array}{l}\text { School } \\
\text { Iunch } \\
\text { (1) }\end{array}$ & $\begin{array}{c}\text { Bag lunch } \\
\text { (2) }\end{array}$ & $\begin{array}{l}\text { P-value of } \\
\text { difference } \\
\text { (3) }\end{array}$ \\
\hline Obese (Fall K) & 0.095 & 0.094 & 0.909 \\
\hline Obese (Spring grade 1) & 0.113 & 0.087 & 0.037 \\
\hline Underweight (Fall Kindergarten) & 0.036 & 0.047 & 0.144 \\
\hline Underweight (Spring grade 1) & 0.029 & 0.037 & 0.307 \\
\hline Birth weight (ounces) & 121.1 & 121.8 & 0.392 \\
\hline Age at Fall $\mathrm{K}$ assessment (months) & 67.9 & 67.8 & 0.601 \\
\hline Mom HS exactly & 0.465 & 0.472 & 0.721 \\
\hline Mom College degree or more & 0.214 & 0.220 & 0.733 \\
\hline Dad HS exactly & 0.372 & 0.344 & 0.116 \\
\hline Dad College degree or more & 0.333 & 0.350 & 0.331 \\
\hline Currently in any non-parental care & 0.519 & 0.477 & 0.012 \\
\hline Hours/week in non-parental care if $>0$ & 17.5 & 16.8 & 0.285 \\
\hline Cost per hour of non-parental care if $>0$ & 6.1 & 6.6 & 0.113 \\
\hline Mom worked before kid entered $\mathrm{K}$ & 0.793 & 0.775 & 0.170 \\
\hline Mom was married when kid born & 0.903 & 0.929 & 0.016 \\
\hline Mother currently married (Spring grade 1) & 0.886 & 0.903 & 0.149 \\
\hline SES (quintiles) & 3.99 & 4.03 & 0.171 \\
\hline Number of siblings & 1.27 & 1.33 & 0.059 \\
\hline Only child & 0.11 & 0.13 & 0.054 \\
\hline Number kid books in house & 100.0 & 107.6 & 0.001 \\
\hline More than 10 kid books & 1.00 & 1.00 & 0.531 \\
\hline Teen mom at first birth & 0.094 & 0.092 & 0.811 \\
\hline Mom 30+ at first birth & 0.247 & 0.272 & 0.104 \\
\hline Math score (Fall K) & 0.423 & 0.451 & 0.414 \\
\hline Math score (Spring grade 1) & 0.404 & 0.390 & 0.647 \\
\hline
\end{tabular}

Notes: White students ineligible for free lunch ONLY, plus school fixed effects interacted with mother's employment status at K entry. 
Table 2: Differences in Obesity Rates by Type of Lunch Eaten

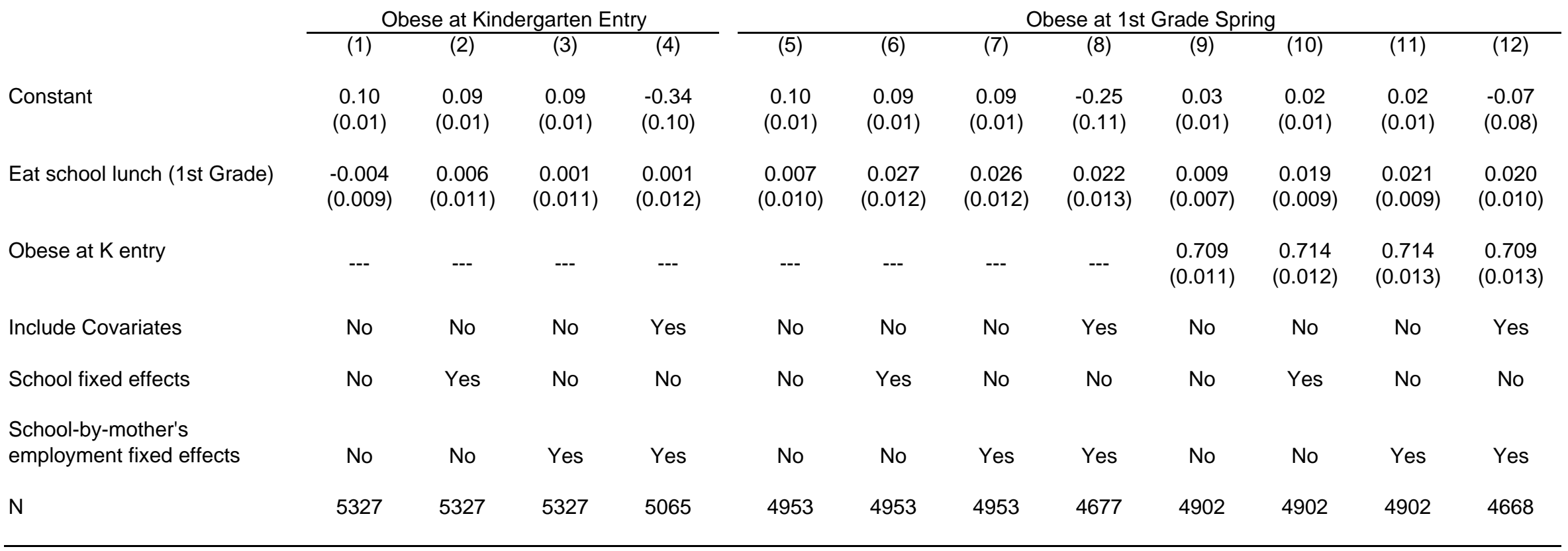

Notes: Linear probability models. Includes only white students ineligible for free lunch. Robust standard errors that allow for correlated residuals across students in the same school in parentheses. 
Table 3: Obesity Rates by Type of Lunch Eaten, Alternate Specifications

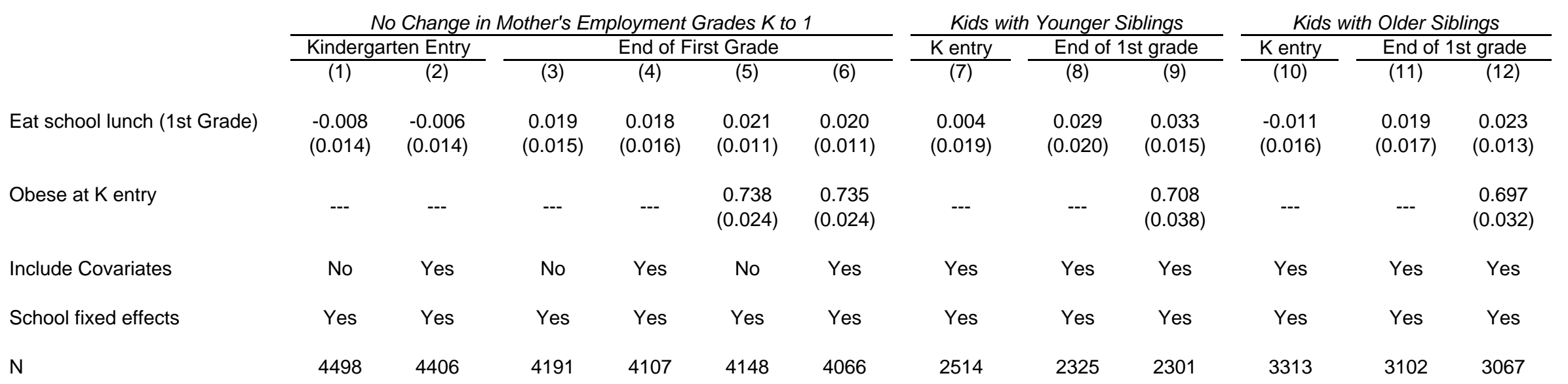

Notes: Linear probability models. Includes only white students ineligible for subsidized lunch. Robust standard errors that allow for correlated residuals across students in the same school in parentheses. 
Table 4: Obesity Growth by Half-Day Kindergarten

\begin{tabular}{|c|c|c|c|c|}
\hline & \multirow{2}{*}{\multicolumn{2}{|c|}{$\frac{\text { Full Day K Half Day K }}{\text { End of Kindergarten }}$}} & \multicolumn{2}{|c|}{ Full Day K Half Day K } \\
\hline & & & End of & st Grade \\
\hline & (7) & (8) & (9) & (10) \\
\hline Eat school lunch (1st Grade) & $\begin{array}{c}0.039 \\
(0.018)\end{array}$ & $\begin{array}{l}-0.008 \\
(0.017)\end{array}$ & $\begin{array}{c}0.058 \\
(0.018)\end{array}$ & $\begin{array}{c}0.010 \\
(0.019)\end{array}$ \\
\hline Include Covariates & Yes & Yes & Yes & Yes \\
\hline School fixed effects & Yes & Yes & Yes & Yes \\
\hline Fixed effects: mom's employmer & Yes & Yes & Yes & Yes \\
\hline $\mathrm{N}$ & 2861 & 2640 & 2822 & 2650 \\
\hline
\end{tabular}


Table 5: Robustness Checks: Alternate Dependent Variables, End of First Grade

\begin{tabular}{|c|c|c|c|c|c|c|c|c|}
\hline & \multicolumn{2}{|c|}{ BMI } & \multicolumn{2}{|c|}{ In(BMI) } & \multicolumn{2}{|c|}{$\begin{array}{l}\text { "At Risk" of Obesity } \\
\text { (85th Percentile) }\end{array}$} & \multicolumn{2}{|c|}{ Obesity "Movers" } \\
\hline & (1) & (2) & (3) & (4) & (5) & (6) & (7) & (8) \\
\hline Eat school lunch (1st Grade) & $\begin{array}{c}0.302 \\
(0.096)\end{array}$ & $\begin{array}{c}0.139 \\
(0.053)\end{array}$ & $\begin{array}{c}0.017 \\
(0.005)\end{array}$ & $\begin{array}{c}0.008 \\
(0.003)\end{array}$ & $\begin{array}{c}0.043 \\
(0.017)\end{array}$ & $\begin{array}{c}0.025 \\
(0.013)\end{array}$ & $\begin{array}{c}0.411 \\
(0.148)\end{array}$ & $\begin{array}{r}0.410 \\
(0.238)\end{array}$ \\
\hline Same weight measure at $\mathrm{K}$ entry & --- & $\begin{array}{l}1.029 \\
(0.019)\end{array}$ & --- & $\begin{array}{c}0.941 \\
(0.021)\end{array}$ & --- & $\begin{array}{c}0.626 \\
(0.016)\end{array}$ & --- & --- \\
\hline Include Covariates & Yes & Yes & Yes & Yes & Yes & Yes & No & Yes \\
\hline School fixed effects & Yes & Yes & Yes & Yes & Yes & Yes & No & No \\
\hline Fixed effects: mom's employment & Yes & Yes & Yes & Yes & Yes & Yes & Yes & Yes \\
\hline $\mathrm{N}$ & 5529 & 5473 & 5529 & 5473 & 5529 & 5473 & 286 & 274 \\
\hline
\end{tabular}

Notes: Includes only white students ineligible for free lunch. Robust standard errors that allow for correlated residuals across students in the same school in parentheses. 


\begin{tabular}{|c|c|c|c|c|}
\hline & $\begin{array}{c}\text { Coefficient } \\
\text { (Standard error) } \\
\text { (1) }\end{array}$ & $\begin{array}{l}\text { P-value } \\
\text { (2) }\end{array}$ & $\begin{array}{c}\text { Mean DepVar, } \\
\text { 185-205\% FPL } \\
\text { (3) }\end{array}$ & $\begin{array}{l}\text { Falsification: } \\
\text { Cutoff }= \\
200 \% \mathrm{FPL} \\
\text { (4) }\end{array}$ \\
\hline $\begin{array}{l}\text { Panel A: Weight outcomes, end of first grade } \\
\text { Obesity indicator }\end{array}$ & $\begin{array}{c}0.040 \\
(0.025)\end{array}$ & 0.099 & 0.125 & $\begin{array}{l}-0.009 \\
(0.029)\end{array}$ \\
\hline $\ln (\mathrm{BMI})$ & $\begin{array}{c}0.022 \\
(0.011)\end{array}$ & 0.046 & 2.82 & $\begin{array}{c}0.010 \\
(0.013)\end{array}$ \\
\hline $\begin{array}{l}\text { Panel B: Lunch participation } \\
\text { Receive free or reduced price lunch }\end{array}$ & $\begin{array}{c}0.258 \\
(0.017)\end{array}$ & 0.000 & 0.418 & $\begin{array}{c}0.115 \\
(0.039)\end{array}$ \\
\hline Eat school lunch & $\begin{array}{c}0.044 \\
(0.013)\end{array}$ & 0.001 & 0.815 & $\begin{array}{l}-0.020 \\
(0.031)\end{array}$ \\
\hline $\begin{array}{c}\text { Panel C: Pre-determined Covariates } \\
\text { Obesity at K entry }\end{array}$ & $\begin{array}{c}0.021 \\
(0.023)\end{array}$ & 0.731 & 0.108 & $\begin{array}{c}0.003 \\
(0.029)\end{array}$ \\
\hline $\ln (\mathrm{BMI})$ at $\mathrm{K}$ entry & $\begin{array}{c}0.003 \\
(0.009)\end{array}$ & 0.355 & 2.78 & $\begin{array}{l}-0.004 \\
(0.011)\end{array}$ \\
\hline Math score & $\begin{array}{c}0.031 \\
(0.061)\end{array}$ & 0.608 & -0.088 & $\begin{array}{l}-0.050 \\
(0.080)\end{array}$ \\
\hline Hispanic & $\begin{array}{c}0.030 \\
(0.025)\end{array}$ & 0.217 & 0.185 & $\begin{array}{c}0.042 \\
(0.031)\end{array}$ \\
\hline Black & $\begin{array}{c}0.006 \\
(0.022)\end{array}$ & 0.779 & 0.145 & $\begin{array}{c}0.024 \\
(0.030)\end{array}$ \\
\hline Has Insurance & $\begin{array}{l}-0.008 \\
(0.027)\end{array}$ & 0.763 & 0.738 & $\begin{array}{l}-0.065 \\
(0.036)\end{array}$ \\
\hline Two-parent family & $\begin{array}{c}0.024 \\
(0.028)\end{array}$ & 0.365 & 0.722 & $\begin{array}{l}-0.053 \\
(0.036)\end{array}$ \\
\hline
\end{tabular}

Notes: Each row represents a separate regression. Other covariates include a 4th degree polynomial in the income/poverty ratio, fully interacted with the indicator variable for income-eligible for free/reduced-price lunch. Huber/White standard errors in parenthesis. $\mathrm{N}=11,541$. 


\section{Table 7: Calories Consumed in NHANES}

Kids < Age 12

\begin{tabular}{cccc}
\hline Lunch & Non-lunch & Lunch & Non-lunch \\
Calories & calories & Calories & calories
\end{tabular}

(3)

(4)

\begin{tabular}{ccc}
\multicolumn{4}{c}{ All Kids 5-16 } \\
\hline Lunch & $\begin{array}{c}\text { Non-lunch } \\
\text { calories }\end{array}$ Calories & Non-lunch \\
Calories & calories
\end{tabular}

\begin{tabular}{lcccccccc} 
School lunch every day & 51.9 & -1.9 & 46.0 & -7.9 & 61.3 & 38.2 & 40.7 & -5.9 \\
& $(22.8)$ & $(37.5)$ & $(23.4)$ & $(38.2)$ & $(26.1)$ & $(42.2)$ & $(26.9)$ & $(42.6)$ \\
Constant & & & & & & & & \\
& 601.9 & 1257.0 & 380.6 & 1266.2 & 593.9 & 1222.9 & 497.3 & 1588.7 \\
Covariates & $(21.1)$ & $(34.7)$ & $(74.8)$ & $(122.3)$ & $(24.2)$ & $(39.2)$ & $(69.0)$ & $(109.6)$ \\
N & No & No & Yes & Yes & No & No & Yes & Yes \\
& 2318 & 2318 & 2318 & 2318 & 3430 & 3430 & 3430 & 3430 \\
\hline
\end{tabular}

Notes: Source: NHANES III. All columns include ageXgender fixed effects. Covariates include race, day of reporting, parents' BMI, family size, and reports of whether consumption is "typical". 


\section{Table 8: Predicted BMI and Overweight}

\begin{tabular}{lccccc} 
& $\begin{array}{c}\text { Baseline } \\
(\text { simulated })\end{array}$ & +40 calories & +60 calories & +75 calories & +120 calories \\
BMI & 16.94 & 17.33 & 17.5 & 17.67 & 18.1 \\
Obesity & 7.7 & 9.4 & 10.4 & 11.3 & 14.9 \\
Increase & --- & 1.7 & 2.7 & 3.6 & 7.2 \\
\hline
\end{tabular}

Note: Standard deviation of BMI is 1.9. Simulation described in text. 
Table 9: Lunch Quality by Average Socio-Economic Status

\begin{tabular}{cccc}
\multicolumn{4}{c}{ Free lunch quartile } \\
\hline 1 & 2 & 3 & 4 \\
705.5 & 624.7 & 613.0 & 612.3 \\
651.2 & 587.6 & 584.5 & 585.8 \\
99.2 & 99.3 & 99.3 & 99.3 \\
78.6 & 78.0 & 85.6 & 88.0 \\
83.9 & 87.8 & 93.2 & 89.9 \\
93.2 & 91.9 & 93.8 & 95.7 \\
77.0 & 80.6 & 81.7 & 82.5 \\
434 & 435 & 435 & 437
\end{tabular}


Figure 1: Graphical Display of Regression Discontinuity Approach, Weight Measures at the end of First Grade
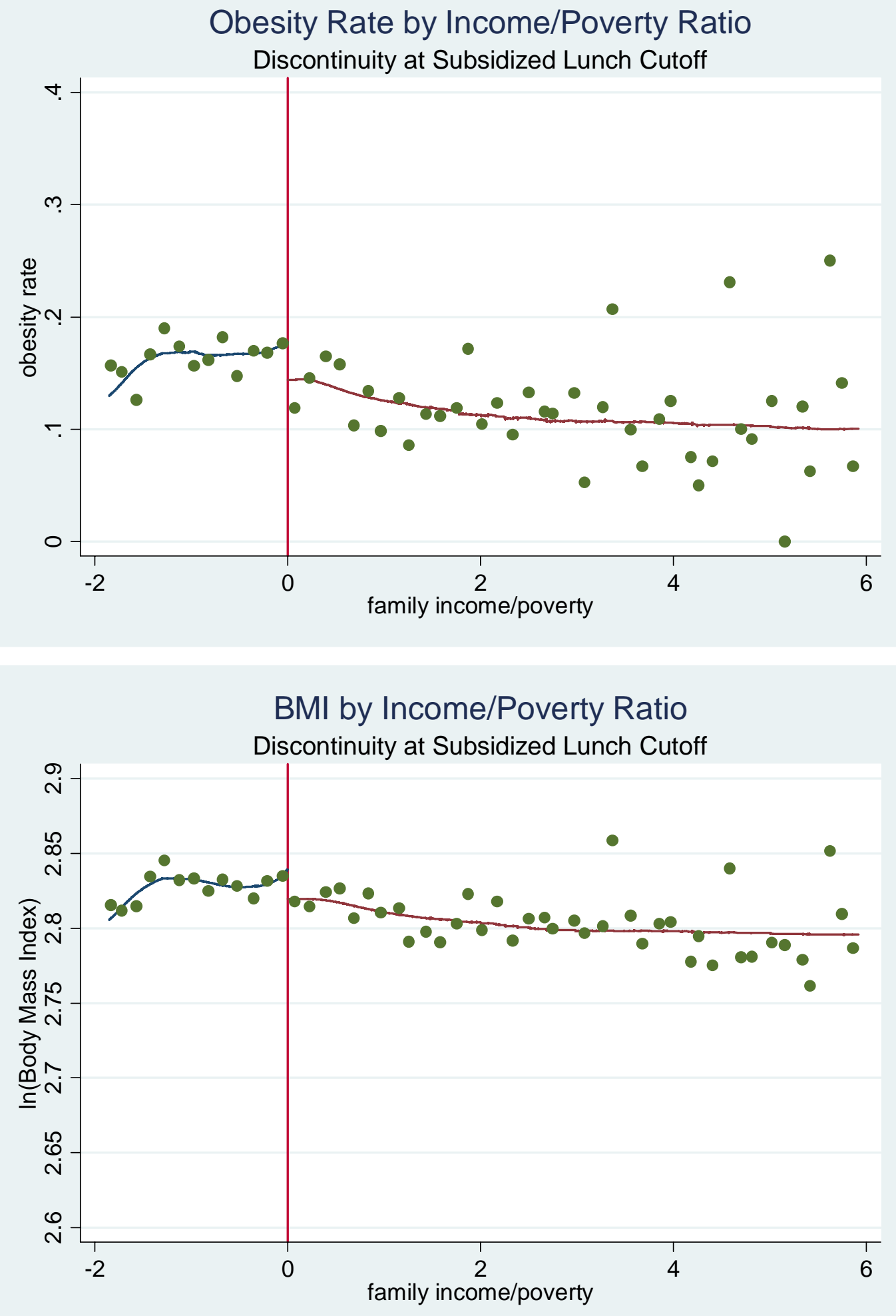


\section{Figure 2: Graphical Display of Regression Discontinuity Approach, Pre-determined variables}
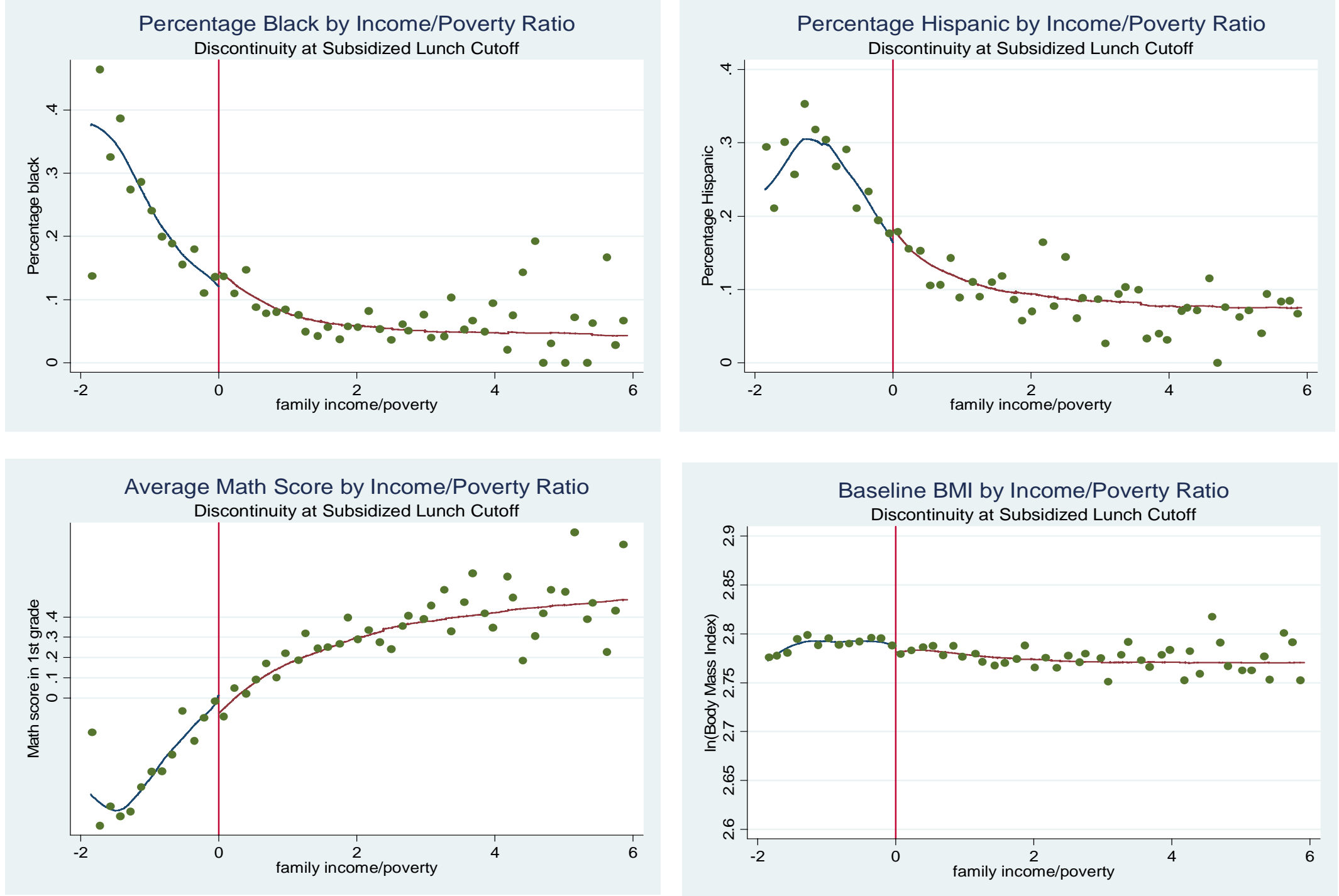